http://jmscr.igmpublication.org/home/ ISSN (e)-2347-176x ISSN (p) 2455-0450 crossref DOI: https://dx.doi.org/10.18535/jmscr/v9i10.01

Journal Of Medical Science And Clinical Research

\title{
Fixation of unstable diaphyseal metacarpal fractures with low profile locking plates: Case series-Current concepts
}

\author{
Authors \\ Kastanis $G^{* 1,2}$, Magarakis $G^{2}$, Kapsetakis $P^{2}$, Pantouvaki $A^{1,3}$ \\ ${ }^{1}$ Reconstructive Hand Surgery Unit, General Hospital of Heraklion -Venizeleio, Crete, Greece \\ ${ }^{2}$ Department of Orthopaedic, General Hospital of Heraklion -Venizeleio, Crete, Greece \\ ${ }^{3}$ Department of Physiotherapy, General Hospital of Heraklion -Venizeleio, Crete, Greece \\ Address: Leoforos Andrea Papandreou 118, Mastambas, Heraklion, 71305, Crete, Greece \\ *Corresponding Author \\ Grigorios Kastanis
}

\begin{abstract}
Metacarpal shaft fractures are a common injury in emergency department, the majority of which are stable injuries that can be treated conservatively with excellent functional results. Injuries, characterized as unstable, need operative management. The aim of this study is to answer the question: is the plate fixation technique the most efficient surgical method for unstable diaphyseal metacarpal fractures, analyzing our functional outcomes in long term period based on time to fracture union, complications and final patient's satisfaction.
\end{abstract}

Material \& Methods: One hundred two patients with 128 unstable metacarpal fractures with an average age of 32,5 years old (range from 22 to 48) were stabilized by low profile plate (locking or convectional) due to unstable metacarpal fracture. Isolated metacarpal fractures appear in $75,5 \%$ of cases while multiple metacarpals involved in 24,5\%. In 15,7\% of the cases the fracture was open classified by Gustilo \& Anderson as Grade I. All patients were operated within the first two weeks from the injury. The approach was dorsal between the spaces of involved metacarpals except in fractures of fifth metacarpal which it was dorsoulnar.

Results: The mean follow-up is about 16,8 months (range from 13 months to 28 months). Results were evaluated according to fracture union, complication, grip strength, completion of VAS score, Quick Dash Score and American Society for Surgery of the Hand (ASSH) Total Active Flexion (TAF). Mean score of pain at final examination according to Visual Analogue Scale was 0, 29+1,08, grip strength was a mean of 92,8\% of the uninjured hand, Quick DASH was 6,8+5,4. The ASSH TAF was excellent in 76 cases (TAF range from 250-280), good in 24 cases TAF range from $185^{\circ}-210^{\circ}$ ) and fair in two cases (TAF were $80^{\circ}$ and $75^{\circ}$ ).

Conclusion: Low profile locking plates offer stable and rigid fixation of the fracture which allow early mobilization and enhance hand functionality. As a surgical method presents complications and in order to avoid all these problems, before the application of locking plate technique, two important factors must be considered: factors according to the fracture pattern, and patients' factors. A second operation to remove the plate should always be on the surgeon's mind when there is evidence of adhesion or joint stiffness.

Keywords: Metacarpal fracture, shaft metacarpal fracture, mini locking plate, internal fixation, complication. 


\section{Introduction}

Hand fractures appear an incidence of $10 \%$ of all human body fractures, while metacarpal fractures appear a percentage of about one-third of all hand fractures. ${ }^{1}$ They are met more often in active working population, between second and third decades of life and present a large economic repercussion in terms of treatment costs and impairment of hand functional incapacity. ${ }^{2,5}$ Males are affected more frequently in relation to females while they perform an increased incidence between May and September which is explained with their participation in sports. ${ }^{17,18}$ The main mechanism of injury is related with direct trauma, or fall onto outstretched hand with a cleaned fist. ${ }^{3}$ Metacarpal bone has a longitudinal-tubular shape and creates a joint system of keystone between the forces of the tendons (extensors-flexors). The index and long finger are articulated with trapezoid and capitate and present limited motion, while metacarpal of the ring and small finger are articulated with hamate and permit remarkable range of flexion-extension and slight rotation. ${ }^{4}$ This variation of carpometacarpal range of motion, influence the quantity of shaft angulation, which will determinate the stability of metacarpal fracture hence the treatment (conservative or surgical). ${ }^{4,5}$

The pattern of metacarpal fractures has been described as transverse (in which the deformity is typical apex-dorsal), as oblique (short or long), as spiral and as comminuted. ${ }^{6,7}$ Day et al(2010) report that three main factors (shortening, dorsal angulation, rotation deformity) determinate the stability of displaced metacarpal fractures. ${ }^{5}$ Unstable metacarpal fracture is defined the fracture which cannot be reduced by closed reduction or cannot maintain the reduction, the multiple metacarpal fractures, and the open fractures. ${ }^{12}$ Kozin et al(2000) report that treatment of metacarpal fracture is guided by the location of the fracture, stability, deformity, and the number of metacarpal fractures. ${ }^{4}$ In literature, many optional surgical techniques have been described for unstable extra-articular metacarpal fractures, including intramedullary nailing, Kirschner wire fixation (Bouquet), intraosseous loop wire fixation, cerclage wire, intramedullary screw fixation, internal fixation with plate(convectional or locking) screws, tension band wiring and mini external fixator. $8,9,10,11,12,13,15,16$

Traditional percutaneous fixation(transfixion, cross, retrograde or antegrade) with Kirschner wire was the first surgical method which has been reported as treatment option of unstable metacarpal fracture because it had two major advantages: minimal surgical expose and ease application technique. ${ }^{14}$ In the last decade with the technological development of implants, there was an increasing trend in the use of low profile plates (initial convectional and after locking) and screws for isolated or multiple extra articular metacarpal fractures provide direct fracture reduction and early range of motion. ${ }^{2,15}$

International literature refers to comparative studies between surgical techniques in management of unstable metacarpal fractures and report the results in terms of assessing tools (Dash score, grip strengths, total active motion(TAM), or aesthetics) which is the only option to compare the advantages and disadvantages of each method. The most well-known complications after plate fixation been reported are mal-union, delay-union, nonunion, stiffness, plate loosening or breakage, complex regional syndrome, tendon adhesion, scarring and infections, while the rate cannot be considered insignificant. ${ }^{19,20,21}$

The aim of this study is to answer the question: Is the plate fixation technique the most competent and efficient surgical method for unstable diaphyseal metacarpal fracture analyzing our functional outcomes in long term (minimum one year), based on time to fracture union, complications(infection, delayed union, nonunion, reoperation) and final patient`s satisfaction?

\section{Material and Methods}

This study was performed at the Orthopaedic department of General Hospital of Heraklion"Venizeleio" from January 2014 to February 
2020. The Institutional Ethical Committee approved the study. Inclusion criteria were: I age $>20$ years old, II diaphyseal metacarpal fractures except thumb, III surgical procedure with open reduction and fixation with only low profile plates-screws used, IV follow-up interval at least one year, $\mathrm{V}$ isolate or multiple unstable metacarpal fractures, VI open grade I metacarpal fractures. Exclusion criteria were: I age $<18$ years old, II patients who received any surgical treatment from another hospital, III corrective osteotomies, IV metacarpal fracture with prior fixation with other techniques, V Intra-articular fractures. Indications for operative treatment were: open fracture gr I, multiple metacarpal shaft fractures, comminuted fractures, fractures with rotational malalignment of digit, shaft angulation $>20^{\circ}-40^{\circ}$ depending on the metacarpal $\left(2^{\text {nd }}-3^{\text {rd }}\right.$ $\left.>20^{\circ}, 4^{\text {th }}>30^{\circ}, 5^{\text {th }}>40^{\circ}\right)$ and shaft shortening $>2 \mathrm{~mm}$.

One hundred two patients with 128 unstable metacarpal fractures with an average age of 32,5 years old (range from 22 to 48) were stabilized by low profile plate (locking or convectional) due to unstable metacarpal fracture. Male patients were the majority of cases with an incidence of $88,2 \%$. The right hand was involved in 63 and the left in 39 cases, while seven cases appeared with bilateral fracture. Fourteen patients presented one or more comorbidities in their clinical history including diabetes mellitus, hypertension, coronary artery disease, chronic obstructive pulmonary disease. Isolated metacarpal fractures appeared in $75,5 \%$ while multiple metacarpals involvement was in $24,5 \%$ of cases. The distribution of multiple fractures was in 10 cases the $3^{\text {rd }}-4^{\text {th }}$ metacarpal $(38,4 \%)$, in 14 cases the $4^{\text {th }}$ $5^{\text {th }}(53,9 \%)$, and the $3^{\text {rd }}-4^{\text {th }}-5^{\text {th }}$ in 2 cases $(7,7 \%)$. (Fig 1) In eleven cases the metacarpal fractures were in polytrauma patients. From the above patients 4 cases had an isolated metacarpal fracture and 7 cases had multiple fractures (two cases with three fractures $2^{\text {nd }}-3^{\text {rd }}-4^{\text {th }}$, three cases with $4^{\text {th }}-5^{\text {th }}$, and the rest with the involvement of the $3^{\text {rd }}$ and $4^{\text {th }}$ metacarpal bone). In $15,7 \%$ of the cases the fracture was open classified by Gustilo \& Anderson as Grade I.(Table I) The causes of fractures were direct blow to hand in 32 cases $(31,4 \%)$, sports in 28 cases $(27,3 \%)$, industrial injuries in 19 cases $(18,7 \%)$, vehicle accidents in 12 cases $(11,8 \%)$, and falls in 11 cases $(10,8 \%)$. (Table II)

The fifth metacarpal bone was the most common in isolated fractures $(38,2 \%)$, while in multiple fractures the combination of the $4^{\text {th }}$ and $5^{\text {th }}$ appeared most frequently.(Table III). Fractures were classified using AO/OTA classification system as Transverse, Oblique/ Spiral and comminuted. Among fracture type, the oblique fracture was more frequent with an incidence of $47 \%$ both in isolated and in multiple cases. (Table IV).

All patients were operated within the first two weeks from the injury. Based on ASA score 30 cases $(29,4 \%)$ were operated under general anesthesia, while the rest of cases with regional $(70,6 \%)$. The patients were placed in supine position with arm tourniquet and fluoroscopic control. The approach was dorsal between the spaces of involved metacarpals. Only in fractures of fifth metacarpal the approach was dorsoulnar. After dissection of subcutaneous tissue, the extensor tendons were relocated radially or ulnarly and in 34 cases the juncturae tendenium was sectioned for better visualization of the fracture line. In majority of cases the periosteum was released from bone and the fracture was reduced by traction of the involved digit. The reduction was secured by reduction clamp and imagining intensifier control was performed. The plates were applied in the dorsal surface of the bone, with the exception of $5^{\text {th }}$ metacarpal fractures in which they were applied on the ulnar surface of the 5th metacarpal bone. When the fracture was long oblique, only three nonlocking bicortical screws were placed to achieve stable fixation. Finally, examination with $\mathrm{C}$-arm intensifier was performed to check the final osteosynthesis (position of the plate, reduction of the fracture and the route of screws in order to not penetrate the flexor 
tendons). The range of motion and fracture stability was examined before skin closure. Sufficient soft tissue closure over the plate was secured to decrease the extensor tendon irritation and also repair the junction tendenium in cases in which it was sectioned. (Fig 2)

Postoperatively a volar cast was applied for two or four weeks, in order to control swelling, pain and enhance soft tissue healing. The stitches were removed in two weeks, while the cast was remained, depending on the comminution of the fracture and the quality of the osteosynthesis, for a varying period of two to four weeks.

A standard rehabilitation protocol program from the first postoperative day was applied in all patients starting from adjacent joints. Active exercises were given for shoulder and elbow joints. Active-assisted exercises were performed in free finger joints while supervised physiotherapy treatment initiated, after immobilization phase and after the cast removal. Continuous passive movement and active assisted exercises in wrist and finger joints were performed initially to restore the range of motion. Patients were trained to follow a personalized home based daily exercise program to increase range of movement and enhance muscle strength and grip strength in a later phase.

\section{Results}

The mean follow-up is about 16,8 months (range from 13 months to 28 months). None of the patients missed out the last re-examination. Patients were assessed in two weeks and in 1,3,6,12 months post surgically. Results were evaluated according to fracture union, determined by follow-up x-Rays, complication, grip strength, Visual Analogue pain Scale, Quick Dash Score and American Society for Surgery of the Hand (ASSH) Total Active Flexion (TAF). The ASSH TAF score presents three grades according to the range of flexion as excellent (flexion $\geq 220^{\circ}$ ), good (flexion $220^{\circ}-80^{\circ}$ ), or poor (flexion $\leq 80^{\circ}$ ).

Radiography examination (anteroposterior lateral and oblique views) were taken postsurgically in
$1,3,6,12$ months and in final assessment. On $\mathrm{x}$ rays is examinated the position of the plate, the union of the fractures and radiological parameters (residual angulation, postoperative shortening). The union of fracture in majority of cases was obtained with an average period of 5,8 weeks (range from 4,2 to 8,5 weeks). Five cases displayed a delay union more than 12 weeks (range from 12-18 weeks). Two cases were with open multiple fractures gr I (one with three fractures and one with two), two cases were polytrauma with diabetes Mellitus type I and comminuted type fractures. The last patients were smoking persons (over 35 cigarettes per day) and had two fractures which one was comminuted and the other short oblique. The paradoxes were that comminuted fracture united in 8 weeks and the oblique in 14 weeks postoperatively. Finally, one case appeared with nonunion of isolated spiral in $2^{\text {nd }}$ metacarpal with breakage of the implant three months postoperatively and the reason for that in our opinion was a new fall which reported by patients and there might be that the plate applied initially on the radial surface of the bone.

Deep infection was appeared in two cases, managed with antibiotics and daily dressing. Out of these two cases, one had three open metacarpal fractures grade I and the other had two open metacarpal fractures and diabetes Mellitus type II. In both cases the implant was removed after union in a mean period of 16,5 weeks. Superficial infection was seen in three cases which managed with antibiotics and daily dressing. The implant was removed in none of these patients with no problems with fracture union. Two cases (one with isolated fracture of the $2^{\text {nd }}$ metacarpal and the other of the $4^{\text {th }}-5^{\text {th }}$ ) presented with complex regional pain syndrome which treated with physiotherapy, non-steroidal anti-inflammatory drugs, and vitamin E. The range of flexion restored after three and five months postsurgically with a mean of $205^{\circ}$.

There were no cases with residual angulation (lateral or anteroposterior) and only one case with postoperative shortening of $4,5 \mathrm{~mm} \quad\left(2^{\text {nd }}\right.$ 
metacarpal) but with no affected range of motion. Three patients had irritation/adhesion of extensor tendon of the second metacarpal. One fracture was comminuted and in the other two cases was spiral. The plate was applied on the dorsum surface of the bone and the end of the plates extended until the subcapital region of the metacarpal which we assume it was responsible for the symptoms. The plates were removed after a mean period of 14.5 weeks. Extensor tenolysis was performed in two cases. After removing the implant, symptoms were ameliorated, and the range of motion increased with no pain. TAF prior second surgical procedure was in a mean of 125 and restored in an average period of four months with a mean of $230^{\circ}$.Stiffness was diagnosed in three cases (two in the second and one in fifth metacarpals). After implant's removal and tenolysis, the TAF restored in a mean of $225^{\circ}$. (Table V).

Mean score of pain at final examination according to Visual Analogue Scale was 0,29 $\pm 1,08$, grip strength was a mean of $92,8 \%$ of the uninjured hand, Quick DASH was $6,8 \pm 5,4$. The ASSH TAF was excellent in 76 cases (TAF range from 250280 ), good in 24 cases (TAF range from $185^{\circ}$ $210^{\circ}$ ) and fair in two cases (TAF were $80^{\circ}$ and $75^{\circ}$ ). From the two cases with fair results, one had the nonunion and the other had two metacarpal fractures (postoperative display complex regional syndrome) and only the little finger appeared with decrease TAF compared with other two metacarpals $\left(3^{\text {rd }}\right.$ and $\left.4^{\text {th }}\right)$.

Analyzing the results, it can be concluded that when there is more than one metacarpal fracture the incidence of infection and delay-union is increased. The percentage of the deep infection arises in combination of open and multiple fractures. Irritation or adhesion of extensor tendons encountered in shaft fracture of the second metacarpal. We consider that when the end of the plate is too close to dorsal subcapital region of the metacarpal bone (especially in $2^{\text {nd }}$ metacarpal), the extensor tendons or the juncturae tendenium (when repaired too tied) impinges over the plate during flexion motion of the digit and this results in pain and in decrease of flexion. In such cases, we suggest the removal of the implant after union of the fractures. In our five presented cases, when the implant was removed the symptoms were ameliorated.

Table I. Demographic characteristics of patients

\begin{tabular}{|l|c|}
\hline Gender (male/female) & $90 / 12(88,2 \% / 11,8 \%)$ \\
\hline Mean Age & $32,7(22-48)$ \\
\hline $\begin{array}{l}\text { Hand Involved } \\
\text { Right/Left) }\end{array}$ & $63 / 39(61,7 \% / 38,3 \%)$ \\
\hline $\begin{array}{l}\text { Hand Dominance } \\
\text { (Right/Left) }\end{array}$ & $75 / 25(75,5 \% / 24,5 \%)$ \\
\hline Open Injuries & $16(15,7 \%)$ \\
\hline Bilateral & $7(6,9 \%)$ \\
\hline Polytrauma & $11(10,8 \%)$ \\
\hline Isolate Fractures & 26 cases $(74,5 \%)$ \\
\hline Multiple Fractures $(24,5 \%)$ \\
\hline \multicolumn{2}{|c|}{ obstructive } \\
\hline Diabetes Mellitus & $5(74,5 \%)$ \\
\hline Hypertension & $6(74,5 \%)$ \\
\hline Coronary artery disease & $3(74,5 \%)$ \\
\hline $\begin{array}{l}\text { Chronic } \\
\text { pulmonary disease }\end{array}$ & \\
\hline
\end{tabular}

Table II. Cause of Diaphyseal Metacarpal Fracture

\begin{tabular}{|l|c|}
\hline \multicolumn{1}{|c|}{ Cause } & Patients \% \\
\hline Falls & $11(10,8 \%)$ \\
\hline Sport Injuries & $28(27,3 \%)$ \\
\hline Direct blow to hand/Fighting & $32(31,4 \%)$ \\
\hline Vehicle Accident & $12(11,8 \%)$ \\
\hline Industrial injuries & $19(18,7 \%)$ \\
\hline
\end{tabular}

Table III. Distribution of metacarpal fractures

\begin{tabular}{|l|c|}
\hline Metacarpal Bones & Patients \% \\
\hline Second & $21(20,6 \%)$ \\
\hline Third & $12(11,8 \%)$ \\
\hline Fourth & $30(29,4 \%)$ \\
\hline Fifth & $39(38,2 \%)$ \\
\hline
\end{tabular}

Table IV. Type of metacarpal fractures

\begin{tabular}{|l|l|}
\hline Metacarpal Bones & Patients \% \\
\hline Transverse & $42(41,2 \%)$ \\
\hline Oblique/ Spiral & $48(47 \%)$ \\
\hline Comminuted & $12(11,8 \%)$ \\
\hline
\end{tabular}

Table V. Complication rates

\begin{tabular}{|l|c|c|}
\hline \multicolumn{1}{|c|}{ Type } & \multicolumn{1}{|c|}{$\begin{array}{c}\text { Isolated } \\
\text { metacarpal } \\
\text { Patients \% }\end{array}$} & $\begin{array}{c}\text { Multiple } \\
\text { metacarpal } \\
\text { Patients \% }\end{array}$ \\
\hline Delay-union & $2(1,9 \%)$ & $3(2,9 \%)$ \\
\hline Nonunion & $1(0,9 \%)$ & 0 \\
\hline Infection Superficial & $2(1,9 \%)$ & $1(0,9 \%)$ \\
\hline $\begin{array}{l}\text { Adhesion/ Irritation } \\
\text { Stiffness }\end{array}$ & $3(4,9 \%)$ & $2(1,9 \%)$ \\
\hline $\begin{array}{l}\text { Complex Pain Regional } \\
\text { Syndrome }\end{array}$ & $2(2,9 \%)$ & 0 \\
\hline
\end{tabular}




\section{JMSCR Vol||09||Issue\|10||Page 01-12||October}

\section{Figure 1}

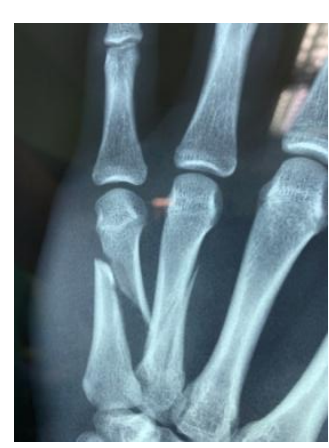

(a)

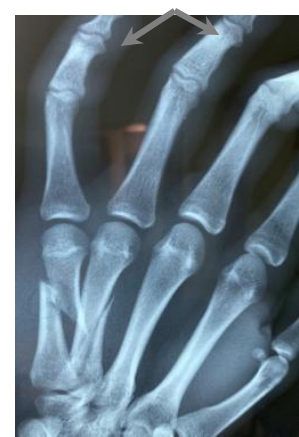

(b)

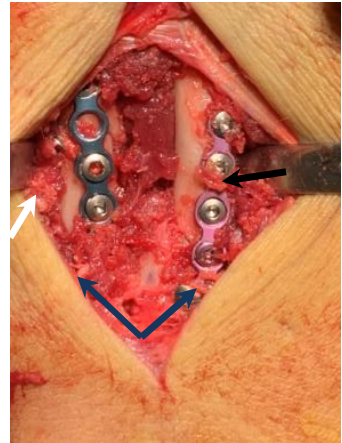

(c)

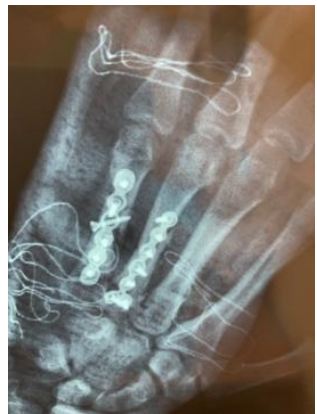

(d)

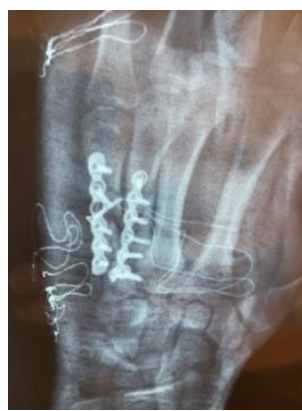

(e)

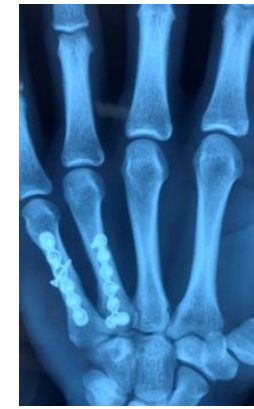

(f)

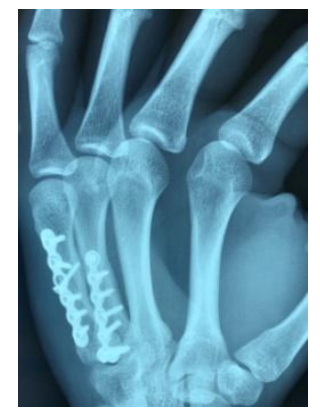

$(\mathrm{g})$

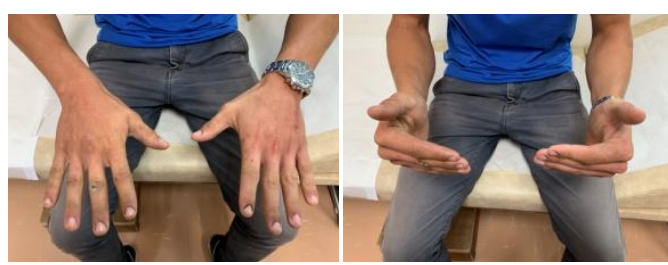

(h)

(i)

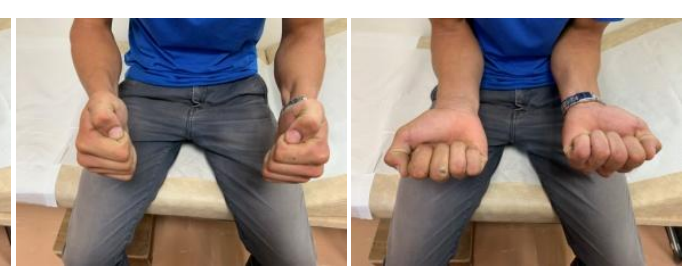

(j)

(k)

Case 1: Male 25 year old after vehicle accident with fractures of $4^{\text {th }}-5^{\text {th }}$ diaphyseal left metacarpals (xRays AP (a) and Oblique (b). Fractures after osteosynthesis (c) with plate low profile (white arrow $5^{\text {th }}$ metacarpal and black arrow $4^{\text {th }}$ metacarpal, blue arrows metacarpal base, grey arrows metacarpal head). Postoperative x-Rays AP (d) and Oblique (e). Union of fractures in x-Rays AP (f) and Oblique(g) in 10 weeks and range of motion at one year(h,i,j,k)

Figure 2

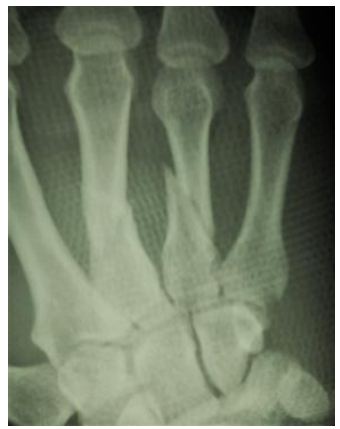

(a)

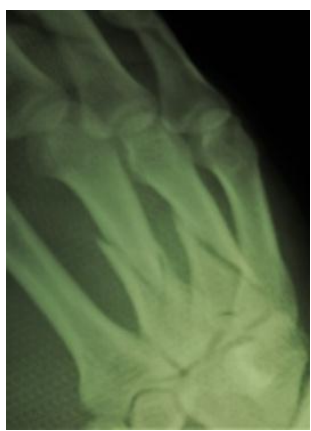

(b)

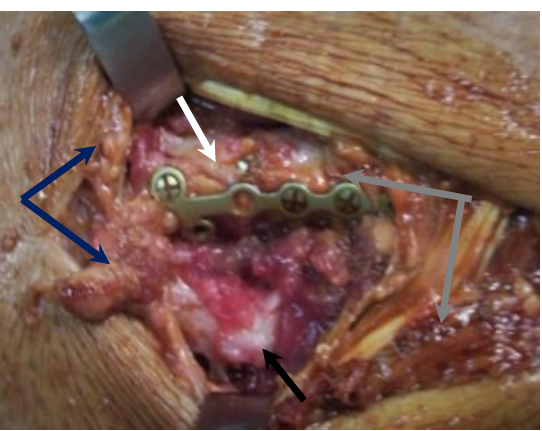

(c) 


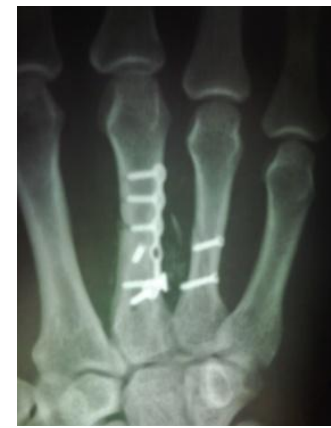

(d)

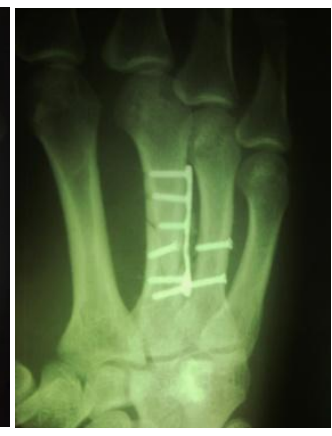

(e)

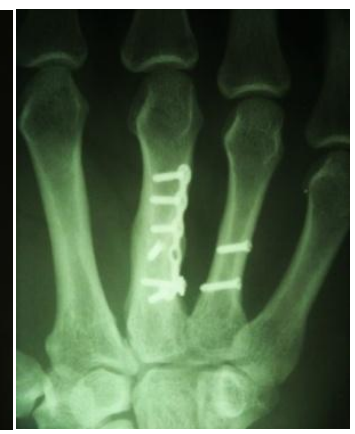

(f)

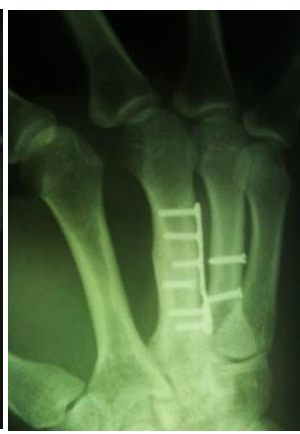

(g)

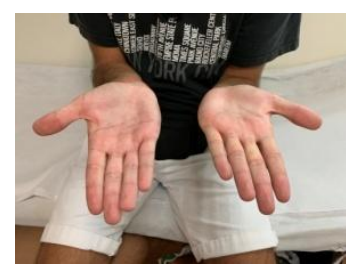

(h)

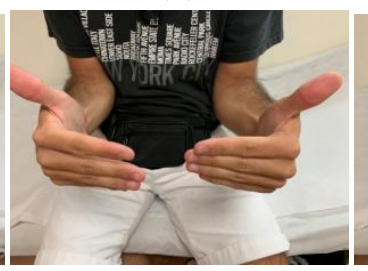

(i)

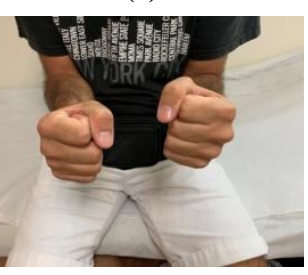

(j)

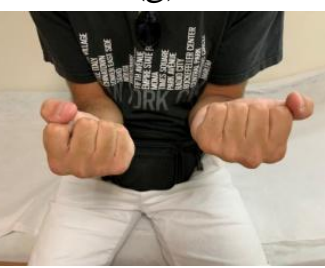

(k)

Case 2: Male 31 year-old after vehicle accident with open grade I fractures of $4^{\text {th }}-3 \mathrm{rd}^{\mathrm{t}}$ diaphyseal right metacarpals (x-Rays AP (a) and Oblique (b). Fractures after osteosynthesis (c) with plate low profile for $3^{\text {rd }}$ metacarpal and lag screws for $4^{\text {th }}$ metacarpal (white arrow $3^{\text {rd }}$ metacarpal and black arrow $4^{\text {th }}$ metacarpal, blue arrows metacarpal base, grey arrows extensor tendons of right middle and ring finger), and $\mathrm{x}$-Rays AP(d) and Oblique(e). Union of fractures in x-Rays AP (f) and Oblique (g) in 9 weeks and range of motion at one year $(\mathrm{h}, \mathrm{i}, \mathrm{j}, \mathrm{k})$

\section{Discussion}

Metacarpal shaft fractures are the most ordinary type of hand fractures in emergency department. The majority of them are stable injuries and can be treated by conservative methods (cast or splint immobilization) with perfect functional results. ${ }^{22}$ Only a 5\% of metacarpal fractures appeared unstable and needed surgical intervention because closed treatment is usually unsatisfactory. ${ }^{21}$ Primary target of the treatment of hand injuries is to restore and maintain anatomic and stable reduction, union of the fracture, and early mobilization to decrease the stiffness and to minimize functional incompetence. There is no evidenced-based aspect regarding the optimal surgical method for unstable extra-articular metacarpal fractures and for this reason many surgical techniques have been proposed in literature. Usually, the choice of method depends on surgeon preferences, skill, and comfort. ${ }^{23}$ Vasilakis et al (2019) support that there are factors (patients, physical examination, individual comorbidities, physical demand, mechanism of injury, injury- to -treatment time, fracture pattern) involved with any technique that requires examination in situation where one method would be clearly advantageous. ${ }^{23}$ Melamed et al (2017) add some other factors such as geographic location of the surgery, level of hospital system, time of the day that the case occur. ${ }^{1}$

Kirschner first designed as set of wires to fix hand fractures, while over the years different techniques based on this material have been developed. ${ }^{24}$ Simple pinning, antegrade, or retrograde was the most popular and familiar surgical method to fixed unstable metacarpal fractures for many years. The advantage of this method is that eschew the stripping of the bone periosteum, does not affect bone vascularization, and permits early mobilization. ${ }^{19}$ Yammine et al (2014) in a metaanalysis study, comparing antegrade versus retrograde intramedullary for fifth metacarpal neck fractures, concluded that the antegrade technique offers some advantages regarding hand function. ${ }^{25} \mathrm{Kim}$ et al (2015) report that the clinical advantage regarding range of motion, VAS, grip strength, and DASH score is better at three months postoperatively, but this is not sustained at 
six months, and he recommended that this method is suitable for patients who require quick rehabilitation in hand function(athletes). ${ }^{26}$ Orbay et al (2006) report a novel method of intramedullary locking nail (LIN)1,1 or 1,6 mm for unstable metacarpal shaft fractures with advantage that proximal locking avoid axial collapse and provides improved rotational stability over simple flexible nails. ${ }^{13}$ In a retrospective study of sixty six patients the researcher report that LIN method has a significant low rate of complication, predictable union time and good functional outcomes. ${ }^{27}$ Mirza et al (2020) in his study with premeasured intramedullary nail, concluded that this technique avoids complications (malunion, secondary fracture displacement, extensor irritation, and backing out) and creates stability of the fracture. ${ }^{31}$

Plate and screws, is the second most familiar surgical technique among hand surgeons with many studies in literature to sign in satisfactory results according to excellent recovery of total active flexion(92\%) for unstable metacarpal fractures, with application of AO mini plates 2,7 $\mathrm{mm} .{ }^{29}$ Page et al(1998) in a retrospective study of 63 metacarpal fractures present complications in $29 \%$ of acute metacarpal fractures and $42 \%$ of metacarpal reconstructions with the most common complications, stiffness nonunion, plate prominence, infection and tendon rupture. ${ }^{30}$

With technology development, mini locking plate in recent years is preferable than open surgical technique for unstable metacarpal fracture. The advanced technology of locking plates, enhance meliorate stability of fixation especially in comminuted and osteoporotic fractures. The additional stability per screw compared with that of non-locked plate enhances its application, and offer early mobilization which decreases edema, muscle weakness, decreases extensor tendon irritation and promotes faster functionality of the hand. ${ }^{1,2}$ Two comparative studies between locking and convectional screws are reported, so first Ochman et al(2010) report the superiority of locking screws that achieve higher stability of fixation and second Barr et al(2013) suggest that there is a biomechanical equivalence between these two implants but with fewer screws whereas there is an opportunity for decreased soft tissue disruption and reduced complication rates. ${ }^{33,34}$ In our study out of 5 cases with delay union, a convectional plate was applied with non-locking screws in 4 patients and in order to restore the stability of the fracture we applied six cortices. There may be a possibility that this extensive periosteal stripping created a disturbance of the blood supply to the metacarpal bone. The other case in which we applied locking screws was an open grade I with multiple fractures and vascularization was disturbed.

In a study of 30 patients with unstable metacarpal fractures(mostly isolated) which were fixed with mini-locked plates the author reported union in all patients with $90 \%$ satisfactory results(excellent or good). ${ }^{2}$ Three patients from this study presented decreased total active motion(TAM) and were comminuted, while regarding the site, it was in $2^{\text {nd }}$ and $5^{\text {th }}$ metacarpals. Aykut et al (2015) in 37 metacarpal fractures reported excellent results $(89,1 \%)$ while 4 cases received a second operation to remove the implant and tenolysis of the extensor tendons but the author did not mention which metacarpal was. ${ }^{35}$ Page et al, in his research reported no difference in TAM in relation to the site of the metacarpal fracture. ${ }^{30}$ In our study 3 cases developed irritation and adhesion of extensor tendon. All cases were in $2^{\text {nd }}$ metacarpal, two fractures were spiral and one comminuted. After removing the plate (nonlocking plate) the TAF was increased. We believe that when the plate is extended in dorsal subcapital region of the bone (especially in the second metacarpal) either to even covered with soft tissue there is friction between plate and extensors tendon or juncturae tendenium. Among stiffness of metacarpophalangeal joint (MCP) the three cases in our results were fixed with convectional and locking (two and one )plate and we consider that plates were massiness and for this reason reduce the ability of the patient(pain) to early range of 
motion which leads to stiffness of MCP joint. These two explanations are assigned to the two types of complications (irritation/adhesion and stiffness on metacarpophalangeal joint). Carreno et al (2020) report that dorsal plates lead to extensor tendon adhesion to plate or tendon rupture, hardware prominence and wood healing problems and in order to avoid or minimize all these problems, they suggest to apply the implant lateral while when applying the plate dorsal to cover the plate with interossei muscles or periosteum or abductor digiti minimi tendon. ${ }^{36}$

Pinning (intramedullary or percutaneous) and mini locking plates are two most familiar surgical techniques for unstable metacarpal fractures and many comparative studies according to the TAM, complication, functional outcomes have been reported in literature with every author to suggest one or the other technique. Fujitany et al(2012) in a comparative study between intramedullary nail versus low profile plate for unstable metacarpal neck fractures concluded that both procedures are highly effective in maintaining fracture restoration in which plate fixation offers early restoration of powerful hand function while intramedullary nail allows a wide range of finger motion. ${ }^{28}$ Dreyfuss et al(2019) comparing the locking plate versus intramedullary pinning in a sample of 74 unstable metacarpal fractures with similar characteristic according fracture patterns suggest that plate fixation offer better results among the stability and early mobilization and avoid tendon irritation while secondary rotation may be addressed with the use of locking intramedullary nail or multiple nails. $^{32}$

Melamed et a 1(2017) in a meta-analysis compared these two methods and report that percutaneous pinning fixation has higher motion scores compared with plates. ${ }^{1}$ Plates offer possibility of early mobilization which results(theoretically) in less edema, muscles weakness and faster recovery of hand function. Functional score, grip strength, time to union and rate of complication were found not to be significantly different between the two treatment groups. ${ }^{1}$ The choice of percutaneous pining versus plating based on fracture patterns, associated injuries, and surgeon preferences. ${ }^{1}$ In another meta-analysis by Zhu et al(2020) the author ends up to the same conclusion that no significant long term differences were noted to the functional outcomes between these two techniques and conclude that the choice of modality should be made based on the skills and preference of the surgeon and availability of resources. ${ }^{37}$ Pandey et al(2019) suggest that Kirschner wire is low cost implant without inherent complication of plating like scar and tendon irritation and must be preferred over plating in shaft metacarpal fractures. ${ }^{38}$

Curtis et al (2015) suggest that plate fixation provide a very stable fixation and required more soft-tissue dissection that other method to avoid complication. Intramedullary nail (IMNs) is an additional option for unstable metacarpal fractures. In multiple transverse or short oblique fractures with association of significant soft tissue trauma and swelling or in unstable polytrauma patients the IMNs is suitable method of treatment. $^{39}$

This study has the following limitations: first we applied two types of plates (mini locking and convectional) which are different according to material and stability and we didn't subgroup the type of fractures when we applicated the plates to have comparative results. Second this study analyzes the results of plate application only and is not a comparative study with another implant. So our presented complication rate or functional outcomes might be different by using some other technique in the same type of metacarpal fracture.

\section{Conclusions}

Metacarpal shaft fractures in majority are stable injuries in which conservative treatment offers good functional results. Only a small percentage of $5 \%$ is unstable fractures and needs operative intervention to restore the bone anatomy. Low profile locking plates offer stable and rigid fixation of the fracture which allow early mobilization and create early hand functionality. 
As a surgical method, presents complications such as tendon adhesion, irritation, rupture, and joint stiffness. To avoid all these problems before application of locking plate technique, two important group factors must be considered: factors according to the fracture pattern, and patients' factors. A second operation to remove the plate should always be on the surgeon's mind (after radiological union) when there is an evidence of adhesion or joint stiffness.

\section{Conflict of interest}

The authors declare that have no conflict of interest.

\section{Ethical Approval}

The Institutional Ethical Committee approved this study.

\section{References}

1. Melamed E, Joo L, Lin E, Perretta D, Capo JT. Plate fixation versus Percutaneous Pinning for unstable metacarpal fractures: A meta-analysis, J Hand Surg Asian Pac Vol.2017;22(1):29-34, doi:10.1142/S0218810417500058.

2. Mohammed Al- Madawy A, Mahmoud Abou Elatta M, Mahmoud Hasanin M, Abd El- Kader Al- Nahal A. The use of minilocked plate for management of unstable metacarpal fractures. J. Hand Microsugr. 2016;8 (3):159-164, doi:10.1055/s-0036-1593730.

3. Fufa DT, Goldfarb CA. Fractures of the thumb and finger metacarpals in athletes. Hand Clin. 2012;28 (3):379-88, doi: 10.1016/j.hcl.2012.05.028.

4. Kozin SH, Thoder JJ, Lieberman G. Operative treatment of metacarpal and phalangeal shaft fractures. J Am Acad Orthop Surg. 2000:8(2):11-21, doi: 10.5435/001246535-200003000-00005.

5. Day CS, Stern PJ. Fractures of metacarpals and phalanges. In: Wolfe SW, Pederson WC, Hotchkiss RN, Kozin SH, Cohen MS, eds. Green's Operative Hand Surgery. 6th ed. Philadelphia, PA: Elsevier Churchill Living stone; 2010:239-290.

6. Stanton JS, Dias JJ, Burke FD. Fractures of the tubular bones of the hand. $\mathrm{J}$ Hand Surg Eur. 2007;32 (6):626-36, doi:10.1016/J.JHSE.2007.06.017.

7. Wu F, Young K, Shahid M, Nightingale P, Choudhary S, Craigen M, Jose R, Foster M. Stability of unicortical versus bicortical metacarpal fracture internal fixation trial( SUBMIT): study protocol for a randomized controlled trial. BMC 2016; 17(1):411, doi: 10.1186/s13063-016-15383.

8. Freeland AE, Orbay JL. Extraarticular hand fractures in adults: a review of new developments. Clin Orthop Relat Res. 2006; 445:133-145. doi:10.1097/ 01 . blo.0000 205888.04200.c5.

9. del Piñal F, Moraleda E, Rúas JS, de Piero GH, Cerezal L. Minimally invasive fixation of the fractures of the phalanges and metacarpals with intramedullary cannulated headless compression screw. J Hand Surg. 2015;40(4):692-700, doi:10.1016/j.jhsa.2014.11.023.

10. Haidukewych GJ. Innovations in locking plate technology. J Am Acad Orthop Surg 2004; 12(4):205-212, doi: 10.5435/00124635-200407000-00001.

11. Al Qattan MM. Metacarpal shaft fractures of the fingers: treatment with interosseous loop wire fixation and immediate postoperative finger mobilization in a wrist splint. J Hand Surg 2006;31(4):377-382, doi:10.1016/j.jhsb.2006.03.166.

12. Margic K. External fixation of closed metacarpal and phalangeal fractures of digits. A prospective study of one hundred consecutive patients. J Hand Surg 2006;31(1):30-40, doi:10.1016/j.jhsb.2005.09.013.

13. Orbay JL, Touhami A. The treatment of unstable metacarpal and phalangeal shaft 
fractures with flexible nonlocking and locking nails, Hand Clin, 2006;22(3):279286, doi:10.1016/j.hcl.2006.02.017.

14. Weinstein LP, Hanel DP. Metacarpal fractures. $\mathrm{J}$ Hand Surgery Am 2002;2(4):168-188, doi:10.1053/jssh.2002.36788.

15. Souer JS, Mugdal CS. Plate fixation in closed ipsilateral multiple metacarpal fractures. J Hand Surg Eur 2008;33(6):740-744, doi:10.1177/1753193408090101.

16. Chiu YC, Hsu CE, Ho TY, Ting YN, Tsai MT, Hsu JT. Effect of figure -of-eight cerclage wire with two Kirschner wires on fixation strength for transvers metacarpal shaft fractures: an in vitro study with artificial bone. BMC Musculoskeletal Disorders 2021;22:431doi:10.1186/s12891-021-04276-8.

17. Nakashian MN, Pointer I, Owens BD, Wolf Jm. Incidence of metacarpal fracture in the US population. Hand 2012;7(4):426430.doi:10.1007/s 11552-012-9442-0.

18. Immerman I, Livermore MS, Szabo RM. Use of emergency department service for hand, wrist, and forearm fractures in the United States in 2008. J Surg Orthop Adv 2014;23(2):98-104, doi:10.3113/jsoa.2014.0098.

19. Diaz -Garcia R, Watljee JF. Current management of metacarpal fractures. Hand Clin 2013;29(4):5-7-539, doi:10.1016/j.hcl.2013.09.004.

20. Fusetti C, Meyer H, Borisch N, Stern R, Santa DD, Papaloizos M . Complications of plate fixation in metacarpal fractures. $\mathrm{J}$ Trauma, 2020;52(3):535-539, doi:10.1097/00005373-200203000-00019.

21. Soni A Gulati A, Bassi JL, Singh D, Saini UC. Outcomes of closed ipsilateral metacarpal fractures treated with mini fragments plates and screws: a prospective study. J Orthop Traumatol 2012;13(1):2933.doi:10.1007/S10195-011-0166-7.
22. Khan A, Giddins G. The outcome of conservative treatment of spiral metacarpal fractures and the role of the deep transverse metacarpal ligaments in stabilizing these injuries. J Hand Surg Eur Vol.2015;40(1):59-62 doi:10.1177/1753193414540408.

23. Vasilakis V, Sinnott CJ, Hamade M, Hamade H, Pinsky BA. Extra-articular metacarpal fractures: Closed reduction and percutaneous pinning versus open reduction and internal fixation. Plast Reconstr. Surg Glob Open.2019:7 (5):e2261, doi:10.1097/GOX.0000000000002261.

24. Weinstein LP, Douglas PH. Metacarpal fractures. J. of the American Society for Surg of the Hand 2002;2(4):168-180, doi:10.1053/jssh.2002.36788.

25. Yammine K, Harvey A. Antegrade intramedullary nailing for fifth metacarpal neck fractures: a systematic review and meta-analysis. Eur J Orthop Surg Traumatol 2014;24(3):273-8, doi:10.1007/s00590-013-1344-5.

26. Kim JK, Kim DJ. Antegrade intramedullary pinning versus retrograde intramedullary pinning for displaced fifth metacarpal neck fractures. Clin Orthop Relat Res 2015;473(5):1747-1754, doi:10.1007/s11999-014-4079-7.

27. Ghazala C, Choudhry N, Rajeev A. Closed intramedullary locking nailing for metacarpal fractures: A retrospective study of sixty-six fractures. Malays Orthop J 2018;21(2):7-14, doi:10. 5704/MOJ.1807.002.

28. Fujitani R, Omokawa S, Shigematsu K, Tanaka Y. Comparison of the intramedullary nail and low profile plates for unstable metacarpal fractures. J Orthop Sci 2012;17(4):450-456, doi:10.1007/s00776-012-0223-y.

29. Bosscha K, Snellen JP. Internal fixation of metacarpal and phalangeal fractures with 
AO mini fragment screws and plates: a prospective study. Injury 1993; 24;24(3):166-168, 10.1016/00201383(93)90283-c.

30. Page SM, Stern PJ. Complications and range of motion following plate fixation of metacarpal and phalangeal fractures. $\mathrm{J}$ Hand Surg Am 1998;23(5):827 -32, doi:10.1016/S0363-5023(98)80157-3.

31. Mirza A, Mirza JB, Thomas TL. Premeasured intramedullary nails for the treatment of metacarpal fractures: Novel instrumentation and technique J Hand Surg Global Online 2020;2(4):250-255, doi:10.1016/jhsg.2020.04.009.

32. Dreyfuss D, Allon R, Izacson N, Hutt D. A comparison of locking plates and intramedullary pinning for fixation of metacarpal fractures. Hand 2019;14(1):2733, doi:10.1177/1558944718798854.

33. Ochman S, Doht S, Paletta J, Langer M, Raschke MJ, Meffert RH. Comparison between locking and nonlocking plates for fixation of metacarpal fractures in an animal model. J Hand Surg, 2010;35(4):597-603, doi:10.1016/j,jhsa.2010.01.002.

34. Barr C, Behn AW, Yao J. Plating of metacarpal fractures with locked or nonlocking screws, a biomechanical study: how many cortices are really necessary? Hand 2013;8(4):454-459, doi:10.1007/s11552-013-9544-3.

35. Aykut S, Öztürk K, Özcan Ç, Demiroğlu M, Gürün AU, Özden E. Results of the surgical treatment in metacarpal shaft fractures using low profile mini plates. Ulus Travma Acil Cerrahi Derg 2015;21(4):279-284, doi:10.5505/tjtes.2015.011651.
36. Carreno A, Ansari MT, Malhotra R. Management of metacarpal fractures. J Clin Orthop Trauma 2020;11(4):554-561, doi:10.1016/j.jcot.2020.05.043.

37. Zhu X, Zhang H, Wu J, Wang S, Miao L. Pin versus plate fixation for metacarpal fractures: a meta- analysis. J Orthop Surg Res 2020;15(1):542-47, doi:10.1186/s13018-020-02057-y.

38. Pandey R, Soni N, Bhayana H, Malhotra R, Pankaj A, Arora SS. Hand function outcome in closed small bone fractures treated by open reduction and internal fixation by mini plate or closed crossed pinning: a randomized controlled trail. Musculoskelet Surg. 2019;103(1): 99-105, doi:10.1007/s12306-018-0542-z.

39. Curtis BD, Fajolu O, Ruff ME, Litsky AS. Fixation of metacarpal shaft fractures: Biomechanical comparison of intramedullary nail crossed k-wires and plate screw constructs. Orthop Surg 2015;7(3):256-260, doi:10.1111/os.12195. 